\title{
Anthropometry, bone mineral density and risk of breast cancer in premenopausal and postmenopausal Saudi women
}

\author{
Nora AlFaris ${ }^{1}$, Nora AlKehayez ${ }^{1}$, Fatema AlMushawah², AbdulRhman AlNaeem ${ }^{2}$, Nadia AlAmri ${ }^{3}$, \\ Ebtisam AlMudawah ${ }^{3}$
}

\section{${ }^{1}$ Princess Nourah bint Abdulrahman University, Riyadh, Saudi Arabia ${ }^{2}$ King Fahad Medical City, Riyadh, Saudi Arabia \\ ${ }^{3}$ King Saud Medical City, Riyadh, Saudi Arabia}

Submitted: 29 February 2020

Accepted: 5 July 2020

Arch Med Sci

DOI: https://doi.org/10.5114/aoms.2020.98676

Copyright (c) 2020 Termedia \& Banach

\section{Abstract}

Introduction: Anthropometry and bone mineral density are linked to hormonal imbalance, which plays a possible role in breast carcinogenesis. The current study was designed to explore the relationship between selected anthropometric and bone mineral density parameters and the risk of breast cancer in premenopausal and postmenopausal Saudi women.

Material and methods: A cross-sectional study was carried out among premenopausal $(n=308)$ and postmenopausal $(n=148)$ women at two Medical Cities in Riyadh, Saudi Arabia from May 2015 to June 2016. Selected anthropometric measurements were obtained from 456 women; 213 of them had breast cancer. Bone mineral density was also measured using dual-energy X-ray absorptiometry.

Results: Greater waist circumference was significantly correlated with a higher breast cancer risk in premenopausal women $(\mathrm{OR}=1.02, p=0.03)$ but not in postmenopausal women. Greater triceps skinfold thickness had been found to be significantly correlated with a higher risk of breast cancer in premenopausal $(\mathrm{OR}=1.06, p=0.001)$ and postmenopausal $(\mathrm{OR}=1.06$, $p=0.001$ ) women. However, bone mineral density was not significantly associated with breast cancer risk in either group of participants.

Conclusions: Breast cancer risk was significantly associated with waist circumference and triceps skinfold thickness in premenopausal women and with only triceps skinfold thickness in postmenopausal women.

Key words: anthropometry, bone mineral density, breast cancer risk, premenopausal, postmenopausal, Saudi Arabia.

\section{Introduction}

Breast cancer is the most common malignancy reported in females worldwide. It considered as the top reason for cancer mortality among females globally [1]. In 2018, about two million cases of breast cancer in females were expected to be diagnosed worldwide, which accounts for almost one-fourth of all cancer cases among women [2]. Fortunately, several developed countries have experienced a fall in breast cancer morbidity and mortality during the past few decades, which was partly attributable to an increase in breast cancer screening and optimal management
Corresponding author: Nora AlFaris

Princess Nourah bint Abdulrahman University Airport Road, King Khalid International Airport Riyadh, Saudi Arabia

E-mail: naalfaris@pnu.edu.sa 
[3-5]. However, the incidence rates of this serious disease continue to rise rapidly, especially in countries that had low incidence rates historically [1]. According to the latest Saudi cancer incidence report, breast cancer was classified as the most frequent malignancy reported in Saudi females who were newly diagnosed with cancer in 2015. It accounted for $16.7 \%$ and $30.1 \%$ of all cancers reported among both genders combined and females at all ages respectively [6]. Although Saudi Arabia has relatively low breast cancer incidence rates at the global level, the available data show that breast cancer incidence rates rise with time among Saudi women [7].

The high burden of breast cancer at the global level inspires extensive literature to explore the risk factors of this disease. Several factors are proved to be commonly linked with an elevated breast cancer risk in women such as factors related to genetics, menstruation, reproduction, exogenous hormone intake, and nutrition [8]. Nevertheless, there are emerging factors thought to contribute to breast cancer risk, such as anthropometry and bone mineral density (BMD) $[9,10]$. Prior research suggested a possible link between breast cancer risk and anthropometric measurements such as body mass index (BMI). Although the outcomes from different studies regarding the nature and the magnitude of such risk factor relationships are still controversial, many studies have reported some association and indicated that this association seems to be interrelated with menopausal status and connected with the levels of steroid hormone in the body [9]. Another evolving risk factor is BMD. Numerous studies have shown that high BMD might be associated with higher breast cancer risk, mainly in postmenopausal females due to long-term estrogen exposure. However, this relationship is still inconclusive and needs further investigation [10].

Natural menopause is defined as the time when female menstrual cycles cease permanently (recognized after one year of amenorrhea) due to agerelated hormonal changes in the reproductive system. It usually occurs at age 49 to 52 years $[11,12]$. Care about women's health should be started at a young age to minimize health problems at older ages [13]. Women experience several somatic and mental changes at menopause that negatively affect their health status and life quality $[14,15]$. Obesity and central obesity are particularly considered as common disturbances associated with menopause $[16,17]$. The key cause of weight gain and body composition changes associated with menopause appears to be the quick reduction in body levels of the specific sex hormone estrogen. In the female body, estrogens stimulate fat accumulation in the subcutaneous tissue, mostly in the femoral and gluteal areas. Contrarily, another sex hormone, androgens, stimulate fat accumulation in the abdominal region. Consequently, the relative hyperandrogenemia concurrent with lack of estrogens during menopause contributes to metabolically unfavorable fat redistribution from a gynoid to android site and thus central obesity development [18]. Another health problem associated with menopause in women is bone loss. Reduction in BMD occurs significantly during late perimenopause and occurs at a similar rate during the early postmenopausal years [19, 20]. Besides the effect of declining estrogen levels at menopause, current evidence suggests that bone loss during the menopausal transition could be linked with a rise in serum follicle-stimulating hormone (FSH) through osteoclastogenesis stimulation leading to bone resorption by osteoclasts [21].

Generally, there are differences between premenopausal and postmenopausal women in terms of breast cancer risk factors [22]. Moreover, there are variations in the relationship between the common risk factors and breast cancer occurrence among different ethnicities [23]. Furthermore, most of the existing literature on different aspects of breast cancer risk factors has been mainly reported for populations from developed countries, whereas these data from Saudi Arabia seem either scattered or not made public [7]. Consequently, discovering risk factors associated with breast carcinogenesis among Saudi women will provide guidance for the needed strategies that could potentially reduce the burden of this serious disease. Therefore, the current study objective is to explore relationships between selected anthropometric and BMD parameters and breast cancer risk among Saudi women after stratification of study subjects based on menopausal status. The current study question is whether there any relationships between anthropometric and BMD parameters and breast cancer risk among premenopausal and postmenopausal Saudi women. We hypothesized that anthropometric and BMD parameters could be associated with breast cancer risk among Saudi women. Also, we suppose that this association could differ depending on menopausal status.

\section{Material and methods}

\section{Study design and participants}

The design of the current study is cross-sectional. In total, 456 women joined the present study between May 2015 and June 2016 from King Saud Medical City $(n=120)$ and King Fahad Medical City $(n=336)$ in Riyadh, the capital city of Saudi Arabia. The study subjects were chosen using the method of systematic random sampling 
from women who visited the surgical clinics to undergo breast cancer screening using mammography. The diagnosis of breast cancer was made by oncologists in the above-mentioned hospitals. The inclusion criteria were: Saudi women aged 20-65 years, not pregnant or lactating at the time of recruitment and who had not been diagnosed with any other malignancy. The recruited subjects had not received any types of therapies before or at the times of recruitment and data collection. The study subjects provided informed written consent in their native language to sign prior to enrollment in line with the Helsinki Declaration. Ethical approval for the study protocol was obtained from the Institutional Review Boards of the King Saud Medical City and the King Fahad Medical City, Riyadh, Saudi Arabia.

\section{Descriptive data collection}

Personal interview by administering a specific questionnaire was adopted to collect descriptive data. These data include selected sociodemographic characteristics: age, education level, employment status, and marital status, and selected lifestyle and maternal characteristics: sunlight exposure and tobacco smoking as well as menopausal status and were collected by trained dietitians from the study participants. The frequency of sunlight exposure was defined as exposure to sunlight three times weekly at least. Each time, at least $20 \%$ of their body surface area had to be exposed to sunlight directly. Presence or absence of menses throughout the previous year or hysterectomy was used to determine menopause status. Postmenopausal women are those with cessation of menstrual periods for at least twelve consecutive months. Health characteristics of participants were collected from their patient medical records.

\section{Anthropometric measurements}

Anthropometric measurements were collected by trained dietitians from the study subjects using standardized methods. Collected anthropometric measurements include body height, body weight, circumferences of waist, hip, and mid-upper arm, skinfold thickness at triceps and body composition (body protein, fat, water, and mineral percentages). The measurement of body height was done with a stadiometer to the nearest $0.1 \mathrm{~cm}$. The measurement of body weight was done with a calibrated weight scale to the nearest $0.1 \mathrm{~kg}$. Body mass index was obtained by dividing weight $(\mathrm{kg})$ by height $\left(\mathrm{m}^{2}\right)$. Participants were considered obese when BMI was equal to 30 or higher. The measurement of waist, hip, and mid-upper arm circumferences was carried out by non-stretchable measuring tape to the nearest
$1 \mathrm{~mm}$. Waist circumference was divided by hip circumference to calculate the waist-hip ratio. Triceps skinfold thickness was measured in duplicate from the left hand with a calibrated skinfold caliper to the nearest $1 \mathrm{~mm}$. Finally, the body composition, including body protein, fat, water, and mineral percentages, was measured using a body fat analyzer (IOI 353, Danilsmc Co., Ltd, South Korea).

\section{Measurement of bone mineral density}

Measurement of BMD was done for all study subjects using dual-energy X-ray absorptiometry (DXA) (Lunar Prodigy, GE Healthcare, United States). Dual-energy X-ray absorptiometry scans were performed in the Department of Radiology at the King Saud Medical City and the King Fahad Medical City, Riyadh, Saudi Arabia. Two sites were selected to measure BMD: the right hip and the lumbar spine (L1 to L4). Bone mineral density values of each participant were automatically compared to ideal BMD, and T-score values (standard deviation from the mean for young adults) were given. Consequently, the bone health status was classified based on WHO criteria as follows: normal (BMD T-score is -1.0 or higher), osteopenia (BMD T-score is between -1.0 and -2.5 ) or osteoporosis (BMD T-score is -2.5 or lower). The bone health status was diagnosed by radiologists.

\section{Statistical analysis}

SPSS version 23 was used to complete data analysis. Statistical analysis was carried out after study subjects were stratified based on menopausal status. Categorical variables were given as frequencies (\%). The normality of variables was investigated using the Shapiro-Wilk test. The $\chi^{2}$ test was used to analyze them. Continuous variables were given as means (SD). The one-way ANOVA test was used to analyze them. The Tukey post hoc test was used to determine significant differences. Univariate logistic regression analysis was performed to detect the factors which might be related to breast cancer risk. Differences were considered statistically significant when $p$ values $<0.05$.

\section{Results}

Four hundred and fifty-six Saudi women (308 premenopausal and 148 postmenopausal) participated in the current study. Selected sociodemographic, lifestyle, maternal and health characteristics of subjects are given in Table I. The average age of premenopausal and postmenopausal subjects was $41.5( \pm 6.2)$ years and $51.7( \pm 5.2)$ years, respectively. Postmenopausal participants had lived about 4 years on average after menopause. About two-fifths of premenopausal participants (39.9\%) and only $14.2 \%$ of postmenopausal participants 
Table I. Sociodemographic, lifestyle, maternal and health characteristics of premenopausal and postmenopausal study subjects

\begin{tabular}{|c|c|c|c|c|c|c|}
\hline \multirow[t]{2}{*}{ Variables* } & \multicolumn{3}{|c|}{ Premenopausal women } & \multicolumn{3}{|c|}{ Postmenopausal women } \\
\hline & $\begin{array}{c}\text { Total } \\
(n=308)\end{array}$ & $\begin{array}{c}\text { No-BC }{ }^{\ddagger} \\
(n=170)\end{array}$ & $\begin{array}{c}\mathrm{BC}^{\ddagger} \\
(n=138)\end{array}$ & $\begin{array}{c}\text { Total } \\
(n=148)\end{array}$ & $\begin{array}{c}\text { No-BC } \\
(n=73)\end{array}$ & $\begin{array}{c}\text { BC } \\
(n=75)\end{array}$ \\
\hline Age (years) & $41.5(6.2)$ & $41.1(6.5)$ & $41.9(5.8)$ & $51.7(5.2)$ & $50.5(5.3)$ & $52.9(5.0)$ \\
\hline Years after menopause & - & - & - & $4.0(5.0)$ & $4.0(5.5)$ & $4.1(4.6)$ \\
\hline \multicolumn{7}{|l|}{ Education level, $n(\%)$} \\
\hline High school or less & $185(60.1)$ & $95(55.9)$ & $90(65.2)$ & $127(85.8)$ & $58(79.5)$ & $69(92.0)$ \\
\hline College or more & $123(39.9)$ & $75(44.1)$ & $48(34.8)$ & $21(14.2)$ & $15(20.5)$ & $6(8.0)$ \\
\hline \multicolumn{7}{|c|}{ Employment status, $n(\%)$} \\
\hline Employed & $131(42.5)$ & $75(44.1)$ & $56(40.6)$ & $23(15.5)$ & $15(20.5)$ & $8(10.7)$ \\
\hline Unemployed & $177(57.5)$ & $95(55.9)$ & $82(59.4)$ & $125(84.5)$ & $58(79.5)$ & $67(89.3)$ \\
\hline \multicolumn{7}{|l|}{ Marital status, $n(\%)$} \\
\hline Married & $241(78.2)$ & $126(74.1)$ & $115(83.3)$ & $107(72.3)$ & $46(63.0)$ & $61(81.3)$ \\
\hline Unmarried & $67(21.8)$ & $44(25.9)$ & $23(16.7)$ & $41(27.7)$ & $27(37.0)$ & $14(18.7)$ \\
\hline \multicolumn{7}{|c|}{ Frequent sunlight exposure, $n(\%)$} \\
\hline No & $82(26.6)$ & $43(25.3)$ & $39(28.3)$ & $43(29.1)$ & $20(27.4)$ & $23(30.7)$ \\
\hline Yes & $226(73.4)$ & $127(74.7)$ & $99(71.7)$ & $105(70.9)$ & $53(72.6)$ & $52(69.3)$ \\
\hline \multicolumn{7}{|l|}{ Tobacco smoking, $n(\%)$} \\
\hline No & $296(96.1)$ & $164(96.5)$ & $132(95.7)$ & $146(98.6)$ & $71(97.3)$ & $75(100)$ \\
\hline Yes & $12(3.9)$ & $6(3.5)$ & $6(4.3)$ & $2(1.4)$ & $2(2.7)$ & $0.0(0.0)$ \\
\hline \multicolumn{7}{|l|}{ Pregnancy history, $n$ (\%) } \\
\hline No & $43(14.0)$ & $30(17.6)$ & $13(9.4)$ & $6(4.1)$ & $4(5.5)$ & $2(2.7)$ \\
\hline Yes & $265(86.0)$ & $140(82.4)$ & $125(90.6)$ & $142(95.9)$ & $69(94.5)$ & $73(97.3)$ \\
\hline \multicolumn{7}{|l|}{ Parity, $n$ (\%) } \\
\hline Nullipara & $46(14.9)$ & $31(18.2)$ & $15(10.9)$ & $7(4.7)$ & $5(6.8)$ & $2(2.7)$ \\
\hline Primipara & $19(6.2)$ & $11(6.5)$ & $8(5.8)$ & $5(3.4)$ & $3(4.1)$ & $2(2.7)$ \\
\hline Multipara & $243(78.9)$ & $128(75.3)$ & $115(83.3)$ & $136(91.9)$ & $65(89.0)$ & $71(91.9)$ \\
\hline \multicolumn{7}{|c|}{ Lactation history (6 months at least), $n(\%)$} \\
\hline No & $65(21.1)$ & $59(34.7)$ & $6(4.3)$ & $18(12.2)$ & $10(13.7)$ & $8(10.7)$ \\
\hline Yes & $243(78.9)$ & $111(65.3)$ & $132(95.7)$ & $130(87.8)$ & $63(86.3)$ & $67(89.3)$ \\
\hline \multicolumn{7}{|l|}{ Diabetes, n (\%) } \\
\hline No & $262(85.1)$ & $144(84.7)$ & $118(85.5)$ & $30(7.4)$ & $12(5.8)$ & $18(9.2)$ \\
\hline Yes & $46(14.9)$ & $26(15.3)$ & $20(14.5)$ & $37(92.6)$ & $18(94.2)$ & $19(90.8)$ \\
\hline \multicolumn{7}{|l|}{ Hypothyroidism, $n$ (\%) } \\
\hline No & $273(88.6)$ & $148(87.1)$ & $125(90.6)$ & $126(85.1)$ & $60(82.2)$ & $66(88.0)$ \\
\hline Yes & $35(11.4)$ & $22(12.9)$ & $13(9.4)$ & $22(14.9)$ & $13(17.8)$ & $9(12.0)$ \\
\hline \multicolumn{7}{|l|}{ Hyperthyroidism, $n$ (\%) } \\
\hline No & $301(97.7)$ & $167(98.2)$ & $134(97.1)$ & $147(99.3)$ & $73(100.0)$ & $74(98.7)$ \\
\hline Yes & $7(2.3)$ & $3(1.8)$ & $4(2.9)$ & $1(0.7)$ & $0(0.0)$ & $1(1.3)$ \\
\hline
\end{tabular}

${ }^{*}$ Categorical variables were expressed as numbers and percentages and continuous variables were expressed as means and standard deviations, ${ }^{\ddagger}$ No- $B C$ - subjects without breast cancer, $B C$ - subjects with breast cancer. 
Table II. Anthropometric and bone health parameters of premenopausal study subjects

\begin{tabular}{|c|c|c|c|c|}
\hline Variables & $\begin{array}{c}\text { Total } \\
(n=308)\end{array}$ & $\begin{array}{c}\text { No-BC } \\
(n=170)\end{array}$ & $\begin{array}{c}\mathrm{BC}^{\ddagger} \\
(n=138)\end{array}$ & $P$ value \\
\hline Weight [kg] & $76.8(16.0)$ & $75.8(16.6)$ & $77.9(15.3)$ & 0.261 \\
\hline Height [cm] & $158.1(9.5)$ & $158.1(10.3)$ & $158.1(8.5)$ & 0.981 \\
\hline BMI $\left[\mathrm{kg} / \mathrm{m}^{2}\right]$ & $30.9(7.2)$ & $30.7(7.9)$ & $31.3(6.3)$ & 0.449 \\
\hline \multicolumn{5}{|l|}{ Obesity, $n(\%)$} \\
\hline No $(B M I<30)$ & $137(44.5)$ & $77(45.3)$ & $60(43.5)$ & 0.750 \\
\hline Yes $(B M I \geq 30)$ & $171(55.5)$ & $93(54.7)$ & $78(56.5)$ & \\
\hline Waist circumference $[\mathrm{cm}]$ & $100.1(15.2)$ & $98.4(16.0)$ & $102.2(14.0)$ & 0.029 \\
\hline Hip circumference $[\mathrm{cm}]$ & $86.9(32.4)$ & $88.3(32.7)$ & $85.1(32.0)$ & 0.380 \\
\hline Waist-hip ratio & $1.32(0.50)$ & $1.27(0.49)$ & $1.38(0.50)$ & 0.069 \\
\hline Triceps skinfold thickness [mm] & $27.9(9.4)$ & $25.8(9.7)$ & $30.6(8.3)$ & 0.001 \\
\hline Mid-upper arm circumference $[\mathrm{cm}]$ & $35.9(9.9)$ & $35.1(10.2)$ & $36.9(9.5)$ & 0.102 \\
\hline Body protein (\%) & $12.1(2.3)$ & $12.2(2.4)$ & $12.0(2.2)$ & 0.424 \\
\hline Body fat (\%) & $36.7(8.2)$ & $36.4(8.4)$ & $37.1(8.1)$ & 0.439 \\
\hline Body water (\%) & $45.6(5.9)$ & $45.8(6.0)$ & $45.3(5.8)$ & 0.432 \\
\hline Body mineral (\%) & $5.6(0.2)$ & $5.6(0.2)$ & $5.6(0.2)$ & 0.539 \\
\hline BMD T-score (at right hip) & $-0.2(1.0)$ & $-0.3(1.1)$ & $0.0(1.0)$ & 0.079 \\
\hline BMD T-score (at lumbar spine) & $-0.4(1.1)$ & $-0.5(1.0)$ & $-0.3(1.1)$ & 0.138 \\
\hline \multicolumn{5}{|l|}{ Bone health status, $n(\%)$} \\
\hline Normal & $197(64.0)$ & $107(62.9)$ & $90(65.2)$ & 0.829 \\
\hline Osteopenia & $101(32.8)$ & $58(34.1)$ & $43(31.2)$ & \\
\hline Osteoporosis & $10(3.2)$ & $5(2.9)$ & $5(3.6)$ & \\
\hline
\end{tabular}

${ }^{*}$ Categorical variables were expressed as numbers and percentages and continuous variables were expressed as means and standard deviations, ${ }^{\ddagger}$ No-BC - subjects without breast cancer, $B C$ - subjects with breast cancer, $B M I$ - body mass index.

had a college degree at least, whereas the education level did not exceed high school for the rest. Similarly, $42.5 \%$ and $15.5 \%$ of premenopausal and postmenopausal participants were employed, respectively. In addition, most of the premenopausal (78.2\%) and postmenopausal (72.3\%) women were married, while the remaining women were unmarried, including single, divorced and widowed women. Frequent sunlight exposure was reported among $73.4 \%$ and $70.9 \%$ of premenopausal and postmenopausal subjects, respectively. Moreover, tobacco smoking was reported by only $3.9 \%$ and $1.4 \%$ of premenopausal and postmenopausal subjects respectively. The vast majority of participants have pregnancy and lactation history. Finally, some participants had been diagnosed with certain endocrine diseases, including diabetes, hypothyroidism and hyperthyroidism.

An analysis of anthropometric and BMD parameters after stratification according to menopausal status revealed a few differences between patients with breast cancer and cancer-free participants in both premenopausal and postmenopausal women (Tables II and III). For premenopausal women, significant differences were found in waist circumference and triceps skinfold thickness. The mean waist circumference in breast cancer patients (102.2 \pm 14.0$)$ was significantly higher than that in cancer-free women $(98.4 \pm 16.0$, $p$ value $=0.029)$. Similarly, the mean triceps skinfold thickness in women with breast cancer (25.8 \pm 9.7$)$ was significantly lower than that in cancer-free women (30.6 $\pm 8.3, p$ value $=0.001)$. For postmenopausal women, a significant difference was only found in triceps skinfold thickness. The mean triceps skinfold thickness in women with breast cancer $(23.4 \pm 10.3)$ was significantly lower than that in cancer-free women $(28.9 \pm 8.6$, $p$ value $=0.001$.

Two anthropometric measurements were found to be significantly correlated with breast cancer risk in premenopausal subjects (see Table IV). 
Nora AlFaris, Nora AlKehayez, Fatema AlMushawah, AbdulRhman AlNaeem, Nadia AlAmri, Ebtisam AlMudawah

Table III. Anthropometric and bone health parameters of postmenopausal study subjects

\begin{tabular}{|c|c|c|c|c|}
\hline Variables & $\begin{array}{c}\text { Total } \\
(n=148)\end{array}$ & $\begin{array}{l}\text { No-BC }{ }^{\ddagger} \\
(n=73)\end{array}$ & $\begin{array}{c}\mathrm{BC}^{\ddagger} \\
(n=75)\end{array}$ & $P$ value \\
\hline Weight $[\mathrm{kg}]$ & $77.0(16.0)$ & $76.2(17.1)$ & $77.7(15.1)$ & 0.578 \\
\hline Height $[\mathrm{cm}]$ & $156.3(9.2)$ & $155.3(8.3)$ & $157.3(10.0)$ & 0.208 \\
\hline BMI & $31.7(7.0)$ & $31.6(6.5)$ & $31.8(7.5)$ & 0.873 \\
\hline \multicolumn{5}{|l|}{ Obesity, $n(\%)$} \\
\hline No $(\mathrm{BMI}<30)$ & $62(41.9)$ & $32(43.8)$ & $30(40.0)$ & 0.636 \\
\hline Yes $(B M I \geq 30)$ & $86(58.1)$ & $41(56.2)$ & $45(60.0)$ & - \\
\hline Waist circumference $[\mathrm{cm}]$ & $103.2(14.7)$ & $105.1(13.3)$ & $101.5(15.9)$ & 0.142 \\
\hline Hip circumference $[\mathrm{cm}]$ & $92.0(33.3)$ & $93.4(33.3)$ & $90.6(33.5)$ & 0.606 \\
\hline Waist-hip ratio & $1.28(0.49)$ & $1.28(0.49)$ & $1.27(0.49)$ & 0.915 \\
\hline Triceps skinfold thickness [mm] & $26.2(9.8)$ & $23.4(10.3)$ & $28.9(8.6)$ & 0.001 \\
\hline Mid-upper arm circumference $[\mathrm{cm}]$ & $37.6(11.1)$ & $37.4(12.9)$ & $37.9(9.0)$ & 0.795 \\
\hline Body protein (\%) & $11.6(2.2)$ & $11.6(1.9)$ & $11.5(2.5)$ & 0.775 \\
\hline Body fat (\%) & $38.9(8.5)$ & $38.7(7.1)$ & $39.1(9.7)$ & 0.763 \\
\hline Body water (\%) & $44.0(6.3)$ & $44.2(5.3)$ & $43.8(7.1)$ & 0.751 \\
\hline Body mineral (\%) & $5.6(0.3)$ & $5.6(0.3)$ & $5.6(0.3)$ & 0.925 \\
\hline BMD T-score (at right hip) & $-0.7(1.0)$ & $-0.8(1.1)$ & $-0.6(0.9)$ & 0.500 \\
\hline BMD T-score (at lumbar spine) & $-1.3(1.3)$ & $-1.2(1.2)$ & $-1.3(1.3)$ & 0.653 \\
\hline \multicolumn{5}{|l|}{ Bone health status, $n(\%)$} \\
\hline Normal & $44(29.7)$ & $26(35.6)$ & $18(24.0)$ & 0.291 \\
\hline Osteopenia & $81(54.7)$ & $36(49.3)$ & $45(60.0)$ & - \\
\hline Osteoporosis & $23(15.5)$ & $11(15.1)$ & $12(16.0)$ & - \\
\hline
\end{tabular}

${ }^{*}$ Categorical variables were expressed as numbers and percentages and continuous variables were expressed as means and standard deviations, ${ }^{\ddagger} \mathrm{No}-B C$ - subjects without breast cancer, $B C$ - subjects with breast cancer, $B M I-$ body mass index.

Greater waist circumference and greater triceps skinfold thickness were significantly linked with a higher breast cancer risk (odds ratio $[\mathrm{OR}]=1.02$, $p=0.03$ and $\mathrm{OR}=1.06, p=0.001$ respectively). A higher waist-hip ratio was correlated with a higher breast cancer risk, but not significantly $(\mathrm{OR}=1.53, p=0.07)$. In postmenopausal women, triceps skinfold thickness was the only anthropometric measurement that was significantly linked with breast cancer risk. Greater triceps skinfold thickness was found to be significantly correlated with a higher breast cancer risk in postmenopausal subjects $(\mathrm{OR}=1.06, p=0.001$; see Table $\mathrm{V})$. On the other hand, the used BMD parameters were not significantly linked with breast cancer risk in premenopausal and postmenopausal participants.

Interestingly, mean waist circumference for osteoporotic patients was significantly different $(p<0.05)$ from that for participants with normal bone health status in both premenopausal and postmenopausal women (see Figure 1). Similarly, mean triceps skinfold thickness for osteoporotic patients was significantly different $(p<0.05)$ from that for participants with normal bone health status in premenopausal women (see Figure 2).

\section{Discussion}

There is substantial inconsistency among different studies in results regarding the connection between anthropometry and BMD and breast cancer risk. Furthermore, this association tends to vary depending on certain population characteristics such as ethnicity and menopausal status [9, 10]. Thus, to capture the most sensitive estimation of risk factor association, research effort needs to stratify analyses based on these characteristics. The current study is the first study investigating the possible relationship between anthropometry and BMD and breast cancer risk in Saudi women.

Anthropometry is among the few modifiable breast cancer risk factors. It is considered crucial in breast cancer etiology [9]. However, a connec- 
Table IV. Risk of breast cancer among premenopausal study subjects for anthropometric and bone health parameters

\begin{tabular}{|c|c|c|c|c|}
\hline \multirow[t]{2}{*}{ Variables } & \multirow{2}{*}{$\begin{array}{l}\text { Odds ratio } \\
(95 \% \mathrm{Cl})\end{array}$} & \multirow[t]{2}{*}{$P$ value* } & \multicolumn{2}{|c|}{$95 \% \mathrm{Cl}$ for odds ratio } \\
\hline & & & Lower & Upper \\
\hline Weight [kg] & 1.01 & 0.26 & 0.99 & 1.02 \\
\hline Height [cm] & 1.00 & 0.981 & 0.98 & 1.02 \\
\hline BMI $\left[\mathrm{kg} / \mathrm{m}^{2}\right]$ & 1.01 & 0.458 & 0.98 & 1.04 \\
\hline \multicolumn{5}{|l|}{ Obesity } \\
\hline No $(\mathrm{BMI}<30)$ & 1 & 0.75 & & \\
\hline Yes $(\mathrm{BMI} \geq 30)$ & 1.08 & & 0.69 & 1.69 \\
\hline Waist circumference [cm] & 1.02 & 0.03 & 1.00 & 1.03 \\
\hline Hip circumference $[\mathrm{cm}]$ & 1.00 & 0.379 & 0.99 & 1.00 \\
\hline Waist-hip ratio & 1.53 & 0.07 & 0.97 & 2.42 \\
\hline Triceps skinfold thickness [mm] & 1.06 & 0.001 & 1.03 & 1.09 \\
\hline Mid-upper arm circumference $[\mathrm{cm}]$ & 1.02 & 0.105 & 1.00 & 1.04 \\
\hline Body protein (\%) & 0.96 & 0.423 & 0.87 & 1.06 \\
\hline Body fat (\%) & 1.01 & 0.438 & 0.98 & 1.04 \\
\hline Body water (\%) & 0.99 & 0.431 & 0.95 & 1.02 \\
\hline Body mineral (\%) & 1.41 & 0.541 & 0.47 & 4.19 \\
\hline BMD T-score (total right hip) & 1.22 & 0.08 & 0.98 & 1.52 \\
\hline BMD T-score (lumbar spine) & 1.18 & 0.139 & 0.95 & 1.46 \\
\hline \multicolumn{5}{|l|}{ Bone health status } \\
\hline Normal & 1 & 0.83 & & \\
\hline Osteopenia & 0.88 & & 0.54 & 1.43 \\
\hline Osteoporosis & 1.19 & & 0.33 & 4.24 \\
\hline
\end{tabular}

${ }^{*}$ Differences were considered statistically significant at $p$ value $<0.05$ and significant values were presented in bold type.

tion between anthropometry and breast cancer risk is still debatable in the literature and is influenced by numerous aspects including ethnicity, reproduction, lifestyle, and menopausal status [24]. Obesity generally influences breast cancer incidence by generating metabolic and hormonal abnormalities, especially in persons with abdominal obesity. Abdominal obesity is linked to insulin resistance. Elevation of insulin level inhibits hepatic production of sex hormone-binding globulin, raises levels of leptin, and reduces adiponectin levels. Additionally, insulin modulates vascular endothelial growth factor expression. The combined effect of these substances accelerates cell divisions and induces synthesis of transcriptional factors which lead to promotion of mammary carcinogenesis [25]. Our data did not reveal any correlation between BMI or obesity and the risk of breast cancer among both groups of subjects, conversely to several previous studies [9, 24]. However, the current study revealed a significant correlation between waist circumference and the risk of breast can- cer in premenopausal women. A similar finding was reported previously [9]. Contrarily, the impact of waist circumference on breast cancer risk is not observed in our results for postmenopausal subjects, in contrast to several previous studies. This finding might be related to a general tendency in elderly women toward central obesity caused by a disturbance in the level of estrogen, unhealthy dietary habits and sedentary lifestyle [26].

Interestingly, our data revealed that triceps skinfold thickness was significantly linked with breast cancer risk in premenopausal and postmenopausal subjects. Another study reported the same result only in premenopausal women [26]. Skinfold thickness is a measure of subcutaneous fat that is assessed as a prediction of the total amount of body fat. Since adipose tissues have a crucial effect on production of female sex steroid hormones, general obesity caused an elevation in the level of estrogen and androgen. Thus, they act in the breast cells as mitogenic agents which contribute to higher breast cancer risk [27]. 
Nora AlFaris, Nora AlKehayez, Fatema AlMushawah, AbdulRhman AlNaeem, Nadia AlAmri, Ebtisam AlMudawah

Table V. Risk of breast cancer among postmenopausal study subjects for anthropometric and bone health parameters

\begin{tabular}{|c|c|c|c|c|}
\hline \multirow[t]{2}{*}{ Variables } & \multirow{2}{*}{$\begin{array}{l}\text { Odds ratio } \\
(95 \% \mathrm{Cl})\end{array}$} & \multirow[t]{2}{*}{$P$ value* } & \multicolumn{2}{|c|}{$95 \% \mathrm{Cl}$ for odds ratio } \\
\hline & & & Lower & Upper \\
\hline Weight [kg] & 1.01 & 0.576 & 0.99 & 1.03 \\
\hline Height $[\mathrm{cm}]$ & 1.02 & 0.210 & 0.99 & 1.06 \\
\hline BMI & 1.00 & 0.872 & 0.96 & 1.05 \\
\hline \multicolumn{5}{|l|}{ Obesity } \\
\hline No $(\mathrm{BMI}<30)$ & 1 & 0.636 & - & - \\
\hline Yes $(\mathrm{BMI} \geq 30)$ & 1.17 & - & 0.61 & 2.25 \\
\hline Waist circumference $[\mathrm{cm}]$ & 0.98 & 0.145 & 0.96 & 1.01 \\
\hline Hip circumference $[\mathrm{cm}]$ & 1.00 & 0.604 & 0.99 & 1.01 \\
\hline Waist-hip ratio & 0.96 & 0.914 & 0.50 & 1.87 \\
\hline Triceps skinfold thickness [mm] & 1.06 & 0.001 & 1.03 & 1.10 \\
\hline Mid-upper arm circumference [cm] & 1.00 & 0.793 & 0.98 & 1.03 \\
\hline Body protein (\%) & 0.98 & 0.774 & 0.84 & 1.14 \\
\hline Body fat (\%) & 1.01 & 0.762 & 0.97 & 1.05 \\
\hline Body water (\%) & 0.99 & 0.749 & 0.94 & 1.04 \\
\hline Body mineral (\%) & 1.05 & 0.924 & 0.36 & 3.06 \\
\hline BMD T-score (total right hip) & 1.12 & 0.497 & 0.81 & 1.55 \\
\hline BMD T-score (lumbar spine) & 0.94 & 0.651 & 0.73 & 1.22 \\
\hline \multicolumn{5}{|l|}{ Bone health status } \\
\hline Normal & 1 & 0.294 & - & - \\
\hline Osteopenia & 1.81 & - & 0.86 & 3.80 \\
\hline Osteoporosis & 1.58 & - & 0.57 & 4.35 \\
\hline
\end{tabular}

${ }^{*}$ Differences were considered statistically significant at $p$ value $<0.05$ and significant values were presented in bold type.

Bone mineral density is considered as a crucial parameter used to evaluate the bone quality and to identify people with osteoporosis, a disease that commonly strikes women, particularly after menopause due to greater bone loss caused by lower levels of estrogen $[10,28]$. Notably, high BMD is a lifetime marker of continued exposure to estrogen, which controls the turnover of bones through suppressing bone resorption and activating specific hormones that stimulate the formation of bones [29]. Furthermore, elevated BMD values have been reported to be related to a higher breast cancer risk. Nonetheless, this relationship is still uncertain [30]. However, no significant correlation was detected in this study between used BMD parameters and risk of breast cancer in premenopausal and postmenopausal subjects. Similar null findings were also observed in a recent long-term follow-up study on postmenopausal women, and a recent dose-response metaanalysis [31, 32].
Interestingly, BMD may be linked with certain factors such as obesity [33]. During the menopausal transition, estrogen levels drop gradually. This causes a loss of bone mass. The situation might be different among obese women due to higher estrogen exposure, which contributes to down-regulating the resorption of bones by restraint of osteoclasts [29]. Furthermore, in obese women who had breast cancer, the outcome is improved due to a high androgen level, which has positive effects on bone tissue. Androgens' action takes place through alteration to estrogen by an enzymatic pathway or through direct binding to androgen receptors [34]. Nevertheless, abdominal obesity causes metabolic complications and low-grade inflammation that could lead to a harmful effect on bone health [33]. Overall, all of these connections are still debatable and open areas for further scientific research.

Finally, the present study is limited by the sampling bias given the study design. However, this 
A

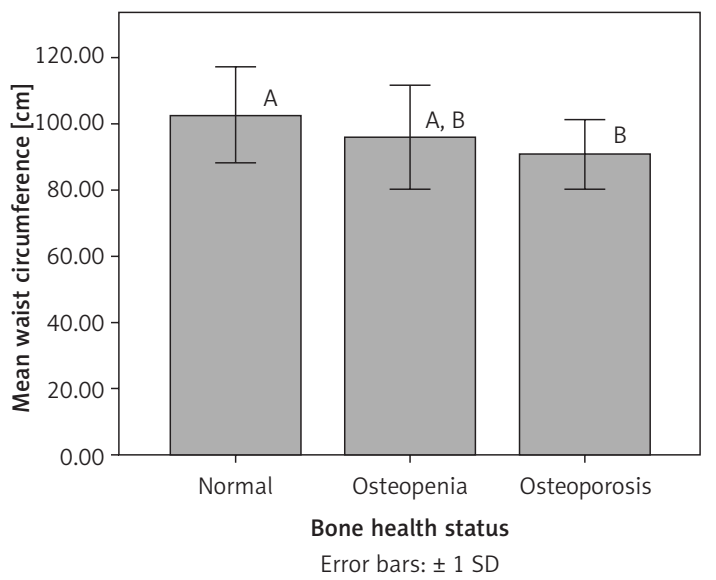

B

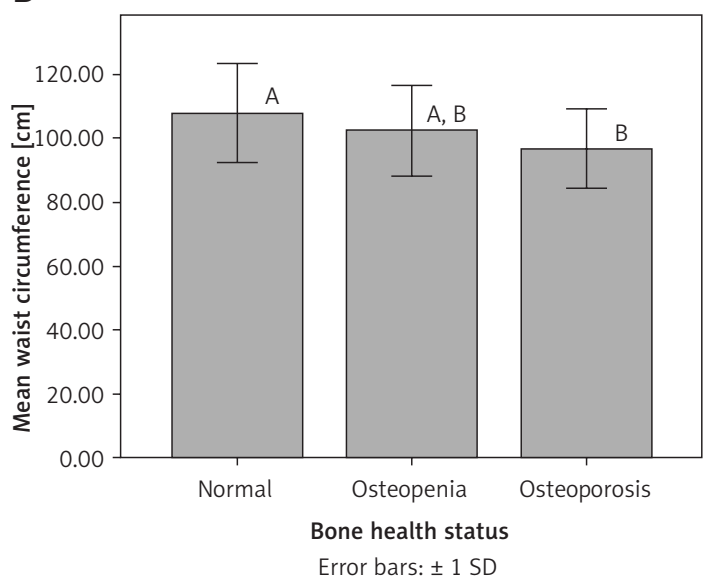

Figure 1. Bar charts illustrated mean waist circumferences for premenopausal women (A) and postmenopausal women (B) based on bone health status. Bars labeled with different letters represent means that significantly different $(p<0.05)$ based on Tukey post hoc test

A

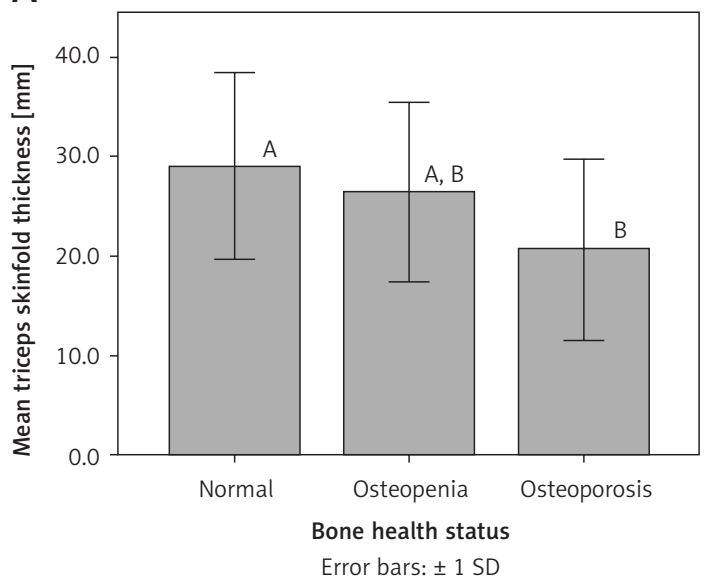

B

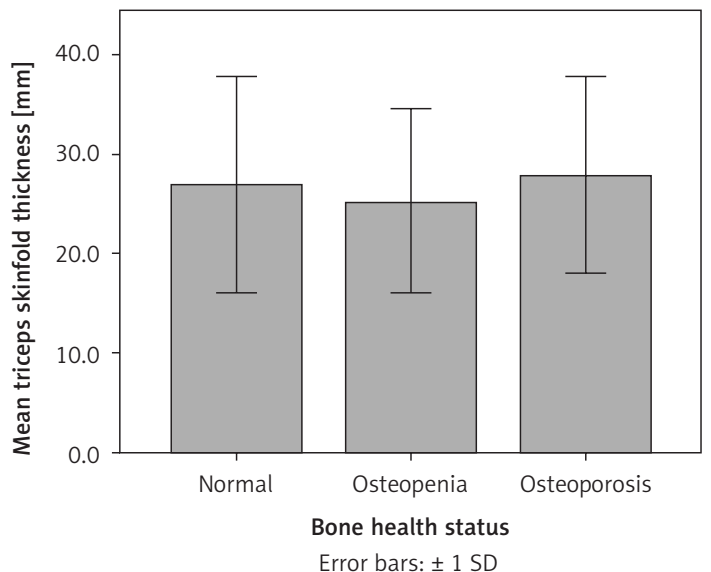

Figure 2. Bar charts illustrated mean triceps skinfold thickness for premenopausal women (A) and postmenopausal women (B) based on bone health status. Bars labeled with different letters represent means that significantly different $(p<0.05)$ based on Tukey post hoc test

study still provides valuable information about the relationships between selected anthropometric and BMD parameters and breast cancer risk among premenopausal and postmenopausal Saudi women.

In conclusion, our study revealed that the risk of breast cancer was significantly associated with waist circumference and triceps skinfold thickness in premenopausal women and with only triceps skinfold thickness in postmenopausal women. Moreover, our results do not support any link between BMD and risk of breast cancer. In light of the contradiction in the available data about the connection between body anthropometric and BMD parameters and risk of breast cancer, a large trial is required, which may allow further understanding of these associations and their mechanistic pathways.

\section{Acknowledgements}

The authors would like to thank King Abdul-Aziz City for Science and Technology (KACST), Riyadh, Saudi Arabia, for the financial support provided to conduct this research (grant number: AT-34-50). This research was funded by the Deanship of Scientific Research at Princess Nourah bint Abdulrahman University through the Fast-track Research Funding Program.

\section{Conflicts of interest}

The authors declare no conflict of interest.

\section{References}

1. Ginsburg O, Bray F, Coleman MP, et al. The global burden of women's cancers: a grand challenge in global health. Lancet 2017; 389: 847-60. 
2. Bray F, Ferlay J, Soerjomataram I, Siegel RL, Torre LA Jemal A. Global cancer statistics 2018: GLOBOCAN estimates of incidence and mortality worldwide for 36 cancers in 185 countries. CA Cancer J Clin 2018; 68: 394-424.

3. Shah R, Rosso K, Nathanson SD. Pathogenesis, prevention, diagnosis and treatment of breast cancer. World J Clin Oncol 2014; 5: 283-98.

4. Woźniacki P, Skokowski J, Bartoszek K, Kosowska A, Kalinowski L, Jaśkiewicz J. The impact of the Polish mass breast cancer screening program on prognosis in the Pomeranian Province. Arch Med Sci 2017; 13: 441-7.

5. Koczkodaj P, Sulkowska U, Gotlib J, Mańczuk M. Breast cancer mortality trends in Europe among women in perimenopausal and postmenopausal age (45+). Arch Med Sci 2020; 16: 146-56.

6. Saudi Cancer Registry. Cancer Incidence Report, Saudi Arabia, 2015. Riyadh, Saudi Arabia: National Health Information Center; 2018.

7. Alattas MT. Cancer control priorities and challenges in Saudi Arabia: a preliminary projection of cancer burden. Gulf J Oncolog 2019; 1: 22-30.

8. Rojas K, Stuckey A. Breast cancer epidemiology and risk factors. Clin Obstet Gynecol 2016; 59: 651-67.

9. Amadou A, Hainaut P, Romieu I. Role of obesity in the risk of breast cancer: lessons from anthropometry. J Oncol 2013; 2013: 906495.

10. Zain NM, Seriramulu VP, Chelliah KK. Bone mineral density and breast cancer risk factors among premenopausal and postmenopausal women - a systematic review. Asian Pac J Cancer Prev 2016; 17: 3229-34.

11. Takahashi TA, Johnson KM. Menopause. Med Clin North Am 2015; 99: 521-34.

12. Monteleone P, Mascagni G, Giannini A, Genazzani AR, Simoncini T. Symptoms of menopause - global prevalence, physiology and implications. Nat Rev Endocrinol 2018; 14: 199-215.

13. Šoštarič A, Jenko B, Kozjek NR, et al. Detection of metabolic syndrome burden in healthy young adults may enable timely introduction of disease prevention. Arch Med Sci 2019; 15: 1184-94

14. Palus GJI, Świst D, Skurzak A, Polska P, Stobnicka D. Impact of menopause on women's health. Medycyna Ogólna i Nauki o Zdrowiu (General Medicine and Health Sciences) 2019; 25: 1-5.

15. López López D, López Martínez NZ, Losa Iglesias ME, Rodríguez Sanz D, Palomo López P, Becerro de Bengoa Vallejo R. Impact on quality of life related to foot health in a sample of menopausal women: a case-control observational study. Climacteric 2016; 19: 501-5.

16. Flegal KM, Carroll MD, Ogden CL, Curtin LR. Prevalence and trends in obesity among US adults, 1999-2008. JAMA 2010; 303: 235-41.

17. Donato GB, Fuchs SC, Oppermann K, Bastos C, Spritzer PM Association between menopause status and central adiposity measured at different cutoffs of waist circumference and waist-to-hip ratio. Menopause 2006; 13: 280-5.

18. Kozakowski J, Gietka-Czernel M, Leszczyńska D, Majos A Obesity in menopause - our negligence or an unfortunate inevitability? Menopause Rev 2017; 16: 61-5.

19. Finkelstein JS, Brockwell SE, Mehta V, et al. Bone mineral density changes during the menopause transition in a multiethnic cohort of women. J Clin Endocrinol Metab 2008; 93: 861-8

20. Cheung E, Tsang S, Bow C, et al. Bone loss during menopausal transition among southern Chinese women. Maturitas 2011; 69: 50-6.
21. Zaidi M, Lizneva D, Kim SM, et al. FSH, bone mass, body fat, and biological aging. Endocrinology 2018; 159: 3503-14.

22. Chauhan P, Yadav R, Kaushal V. Breast cancer risk factors according to menopausal status. Online Journal of Health and Allied Sciences 2017; 16: 3.

23. Parise CA, Caggiano V. Disparities in race/ethnicity and socioeconomic status: risk of mortality of breast cancer patients in the California Cancer Registry, 2000-2010. BMC Cancer 2013; 13: 449.

24. Amadou A, Ferrari P, Muwonge R, et al. Overweight, obesity and risk of premenopausal breast cancer according to ethnicity: a systematic review and dose-response meta-analysis. Obes Rev 2013; 14: 665-78

25. Rose DP, Gracheck PJ, Vona-Davis L. The interactions of obesity, inflammation and insulin resistance in breast cancer. Cancers 2015; 7: 2147-68.

26. Pacholczak R, Klimek-Piotrowska W, Kuszmiersz P. Associations of anthropometric measures on breast cancer risk in pre-and postmenopausal women - a case-control study. J Physiol Anthropol 2016; 35: 7

27. Simone V, D'avenia M, Argentiero A, et al. Obesity and breast cancer: molecular interconnections and potential clinical applications. Oncologist 2016; 21: 404-17.

28. Kopiczko A. Bone mineral density in old age: the influence of age at menarche, menopause status and habitual past and present physical activity. Arch Med Sci 2020; 16: 657-65.

29. Manolagas SC, O'Brien CA, Almeida M. The role of estrogen and androgen receptors in bone health and disease. Nat Rev Endocrinol 2013; 9: 699-712.

30. Nagel G, Peter RS, Klotz E, Brozek W, Concin H. Bone mineral density and breast cancer risk: results from the Vorarlberg Health Monitoring \& Prevention Program and meta-analysis. Bone Rep 2017; 7: 83-9.

31. Brozek W, Nagel G, Ulmer H, Concin H. Bone mineral density and breast cancer incidence and mortality in postmenopausal women: a long-term follow-up study. J Womens Health 2018; 28: 628-35.

32. Chen JH, Yuan Q, Ma YN, Zhen SH, Wen DL. Relationship between bone mineral density and the risk of breast cancer: a systematic review and dose-response meta-analysis of ten cohort studies. Cancer Manag Res 2019; 11: 1453-64.

33. Gower BA, Casazza K. Divergent effects of obesity on bone health. J Clin Densitom 2013; 16: 450-4.

34. Vandewalle $S$, Taes $Y$, Van Helvoirt $M$, et al. Bone size and bone strength are increased in obese male adolescents. J Clin Endocrinol Metab 2013; 98: 3019-28. 